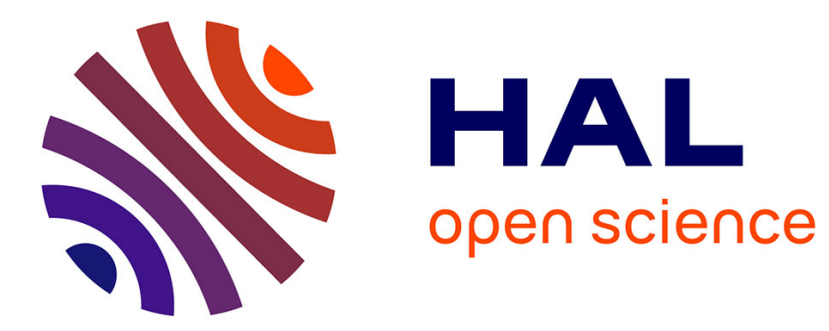

\title{
New Investigations in Play Static Hysteresis Model for Increased Accuracy and Robustness
}

Arnaud Cariou, A. Kedous-Lebouc, Christian Chillet, Laurent Albert, Teodor Wisniewski, Sergi Riba

\section{- To cite this version:}

Arnaud Cariou, A. Kedous-Lebouc, Christian Chillet, Laurent Albert, Teodor Wisniewski, et al.. New Investigations in Play Static Hysteresis Model for Increased Accuracy and Robustness. IEEE Transactions on Magnetics, 2021. hal-03377494

\section{HAL Id: hal-03377494 https://hal.science/hal-03377494}

Submitted on 22 Nov 2021

HAL is a multi-disciplinary open access archive for the deposit and dissemination of scientific research documents, whether they are published or not. The documents may come from teaching and research institutions in France or abroad, or from public or private research centers.
L'archive ouverte pluridisciplinaire HAL, est destinée au dépôt et à la diffusion de documents scientifiques de niveau recherche, publiés ou non, émanant des établissements d'enseignement et de recherche français ou étrangers, des laboratoires publics ou privés. 


\title{
New investigations in Play static hysteresis model for increased accuracy and robustness
}

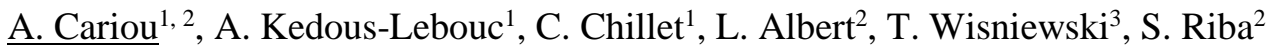 \\ ${ }^{1}$ Univ. Grenoble Alpes, CNRS, Grenoble INP*, G2Elab, F-38000 Grenoble, France \\ ${ }^{2}$ MEA department, IRT Saint-Exupery, B612 3 rue Tarfaya, 31405 Toulouse, France \\ ${ }^{3}$ Leroy Somer Motors, Angoulême, France
}

\begin{abstract}
This paper presents an evolution of the inverse Play model to reconstruct static hysteresis from a flux density waveform input. It is to be combined with dynamic and 2D or 3D models to estimate complete iron loss in electrical machines.

In the first part of the article, the paper shows the significant improvement on the original inverse Play model accuracy obtained by modifying the characterization measurements methodology, the subsequent discretization and the identification method.

Thereafter, a new version of the Play model, named "continuous", is introduced, which allowed a significant gain in performance at the expense of a greater computation time for the identification process.

Both model versions have been validated though experimental comparison. All measurements, characterization and validation, have been done according to IEC60404-2 on two different test laboratories. The studied material is non-oriented SiFe M400-50A electrical steel.
\end{abstract}

Index Terms - hysteresis modeling, Play hysteron, discrete and continuous function, iron loss

\section{INTRODUCTION}

$\mathrm{E}$ LECTRIC POWER embedded in airplanes has continuously increased over the last decades. Indeed, electric systems have been replacing pneumatic or hydraulic systems, as they present advantages mainly in terms of availability, reliability and lighter maintenance.

According to this demand, electric machines have to provide even more power respecting strict constraints mainly on volume, weight and efficiency. The higher power density requirements result most often in higher electrical frequency machines and the consequent significant increase of the iron loss, which may become dominant in the machine [1].

Numerous variations of iron loss models have been developed. Analytical models such as Bertotti [2], Steinmetz [3] and their derivatives are often used. They are easy to characterize but can be less accurate, especially in electrical machines where phenomena such as strong harmonic content, DC bias excitation or rotational effect must be taken into account. Hysteresis models such as Preisach [4], Jiles-Atherton [5], Congruency-based model [6], or statistical model [7] or Play \& Stop [8] are more accurate in this case but require more experimental data and computation time.

For our study, hysteresis models appear to be more suitable to predict accurately iron loss with reasonable computation time. This paper presents a scalar static model of hysteresis based on Play hysteron.

\section{THE INVERSE PLAY MODEL}

\section{A. Principle}

Bobbio et al. presented the Play \& Stop model in [8]. The model represents the hysteresis as a series association of mathematical operators called hysterons. In the inverse Play model, an identification procedure based on experimental measures allows to calculate the magnetic field (1):

$$
H(t)=\sum_{i=1}^{M} h_{i}\left(p_{i}(B(t))\right)
$$

Where $\mathrm{H}(\mathrm{t})$ and $\mathrm{B}(\mathrm{t})$ are time-varying signals of the magnetic field and the flux density, $M$ is the number of hysterons, $h_{i}$ is the $i^{\text {th }}$ shape function and $p_{i}$ is the $i^{\text {th }}$ Play operator (2):

$$
p_{i}(B(t))=\max \left(\min \left(p_{i}^{0}, B+\epsilon\right), B-\epsilon\right)
$$

Where $\mathrm{p}_{\mathrm{i}}^{0}$ is the play operator at the previous time step and $\varepsilon$ is the threshold value.

The initial identification method consists in defining an incidence matrix from the experimental dataset and solve (3):

$$
C . h_{i}=H_{\text {measured }} \Leftrightarrow h_{i}=C^{-1} . H_{\text {measured }}
$$

Where $\mathrm{C}$ is the incidence matrix, $\mathrm{h}_{\mathrm{i}}$ is the vector of the shape functions values and $\mathrm{H}_{\text {measured }}$ are the measured values of the magnetic field from the characterization. This process is equivalent to fit the measured field to the modeled ones and so calculate the shape function of all hysterons.

As the Play model and Preisach model are mathematically equivalent, similar identification methods can be used for both models, For example, the function [7] allows to reduce the identification time [8] by removing the calculus of the double integral of Preisach model.

\section{B. Experimental measurements set}

Usually, one can identify Play \& Stop models from a set of symmetrical hysteresis loops of increasing amplitudes. An improved identification of the Play model has been proposed in [9] considering a set of asymmetrical loops and a major one. These asymmetrical loops correspond to the First-Order Reversal Curves (FORCs) of the major loop as shown in Fig. 1. 

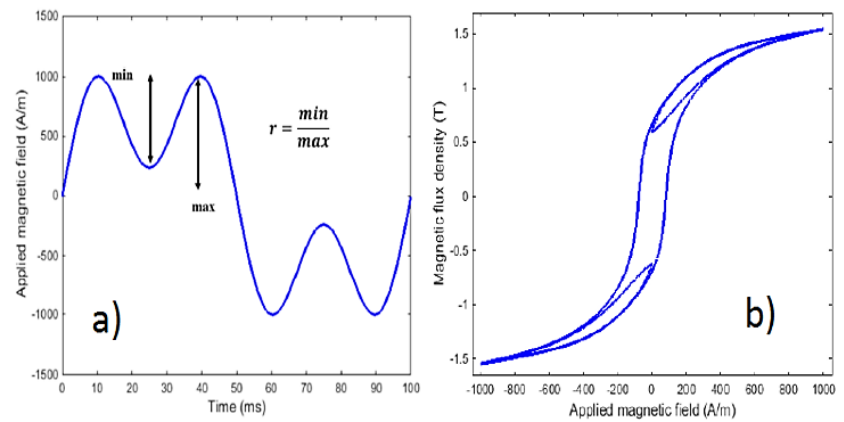

Fig. 1. Characterization waveform a) and corresponding cycle b) in [9]

The study proposes a sinusoidal waveform with a $3^{\text {rd }}$ harmonic to obtain different FORCs. The frequency is as low as possible but errors can appear as reversal points have the same B value but each FORC can have different $\mathrm{dB} / \mathrm{dt}$ value.

\section{New characterization measurements}

FORCs are obtained from a triangular flux density waveform as shown in Fig. 2. Thus, each reversal point has the same $|\mathrm{dB} / \mathrm{dt}|$.

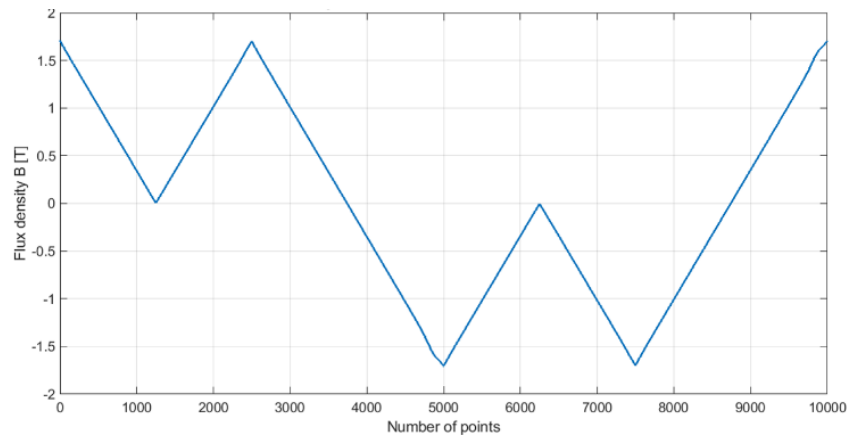

Fig. 2. New characterization flux density waveform

With such a waveform, all reversal points are situated on the major loop, reducing the overall error of the identification process.

\section{IDENTIFICATION PROCESS MODIFICATIONS}

\section{A. Hysteron refinement process}

Least square method allows to perform an over-discretization. To increase accuracy, especially for low amplitude variations, the number of hysterons has to be maximized and the threshold value reduced. Thus, with the same experimental data, hysterons are added by the following methods:

- Regularly subdividing of the step; mostly the linear part of the hysteresis discretization is refined.

- Specifying a maximal magnetic field value between two consecutive steps, which allows a better reconstruction of the saturated part of the hysteresis.

This process has some limitations: especially, it lowers the condition number of the matrix $\mathrm{C}$ causing numerical errors.

\section{B. Experimental data pre-processing}

Previous modifications already show improvements, i.e. the mean square error (MSE) (4) decreases:

$$
\epsilon=\left\|C \cdot h_{i}-H_{\text {measured }}\right\|^{2}
$$

Nevertheless, a pre-processing data is added to ensure that no points of any FORC could be outside the major loop. As shown in Fig. 3, experimental uncertainties (here mostly the offset regulation of the experimental bench supply) can disrupt the dataset and increase error.

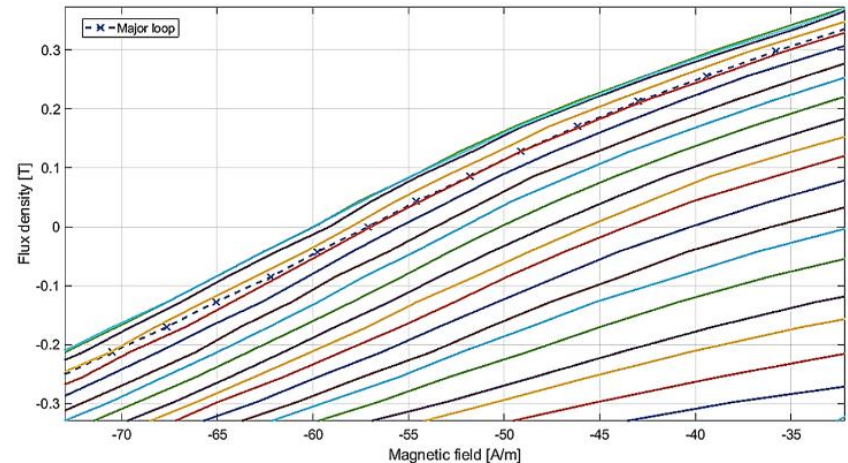

Fig. 3. Zoom on major (dotted line) and FORCs (continuous lines) from experimental data before processing

Thus, the FORC is forced to be on the major loop when $\left|\mathrm{H}_{\text {Major }}-\mathrm{H}_{\mathrm{FORC}}\right|$ is less than $2 \%$ of the major value as shown in Fig. 4.

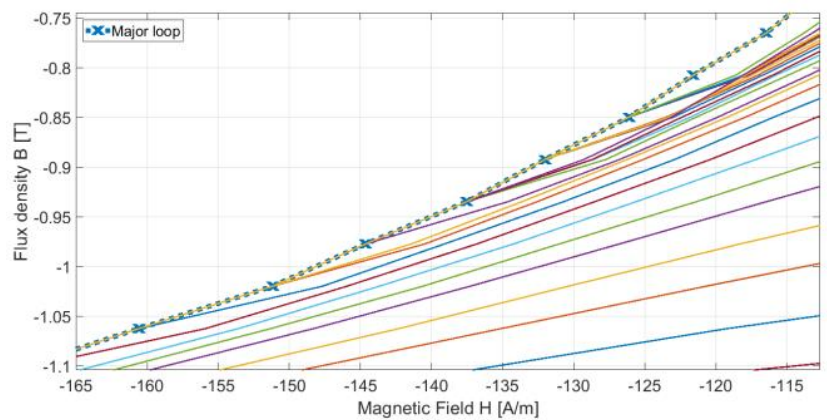

Fig. 4. Zoom on major (dotted line) and FORCs (continuous lines) from experimental data after processing

In addition, a weighted (5) least square approach is investigated to favor low magnetic field values in the reconstruction:

$$
W=\operatorname{diag}\left(\max \left(\left|H_{\text {measured }}\right|\right)+1-H_{\text {measured }}\right)
$$

\section{RESULTS AND LIMITS OF THE DISCRETE MODEL}

\section{A. Results}

This model is identified for the M400-50A SiFe material and tested by comparison with various experimental measurements. Model identification is performed using 37 FORCs, $\mathrm{M}=40$ and $\varepsilon=0.0425 \mathrm{~T}$. Fig. $5-8$ present some measured and reconstructed cycles while Table 1 gives the corresponding loss estimation errors.

TABLE 1. RELATIVE ERRORS ON LOSS CALCULATION

$$
\Delta P \%=100 \cdot \frac{P_{\text {model }}-P_{\text {measured }}}{P_{\text {measured }}}
$$

\begin{tabular}{|c|c|c|c|c|}
\hline & Fig. 5. & Fig. 6. & Fig. 7. & Fig. 8. \\
\hline$\Delta P \%$ & $-5.3 \%$ & $-0.2 \%$ & $-1.3 \%$ & $19 \%$ \\
\hline
\end{tabular}




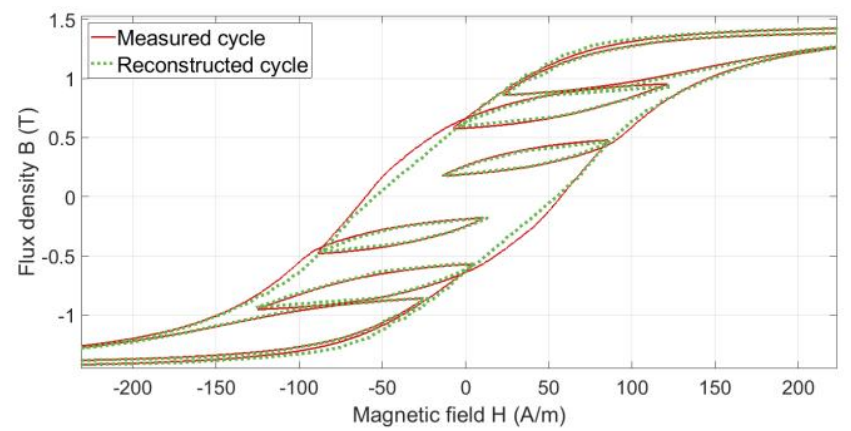

Fig. 5. Measured and reconstructed $1.7 \mathrm{~T}$ cycle with $9^{\text {th }}$ harmonic at $30 \%-90^{\circ}$

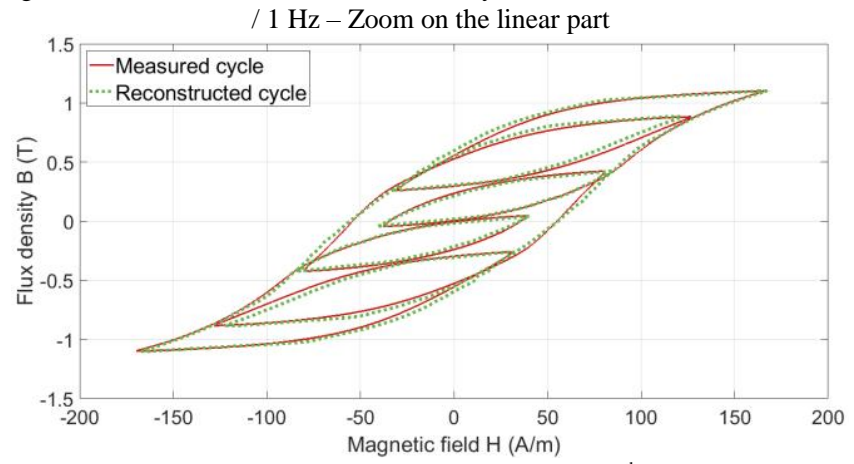

Fig. 6. Measured and reconstructed $1.1 \mathrm{~T}$ cycle with $5^{\text {th }}$ harmonic at $60 \%$ $100^{\circ} / 1 \mathrm{~Hz}$

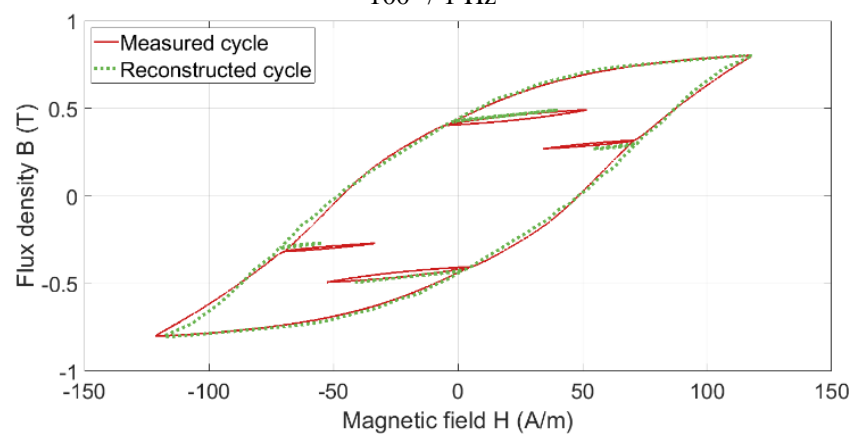

Fig. 7 . Measured and reconstructed $0.8 \mathrm{~T}$ cycle with $5^{\text {th }}$ harmonic at $25 \%-45^{\circ}$ / $1 \mathrm{~Hz}$

The model has mostly less than $10 \%$ relative error on loss calculation. In Fig. 8, a very low amplitude loop is considered. In this worst case, the relative error can reach about $20 \%$.

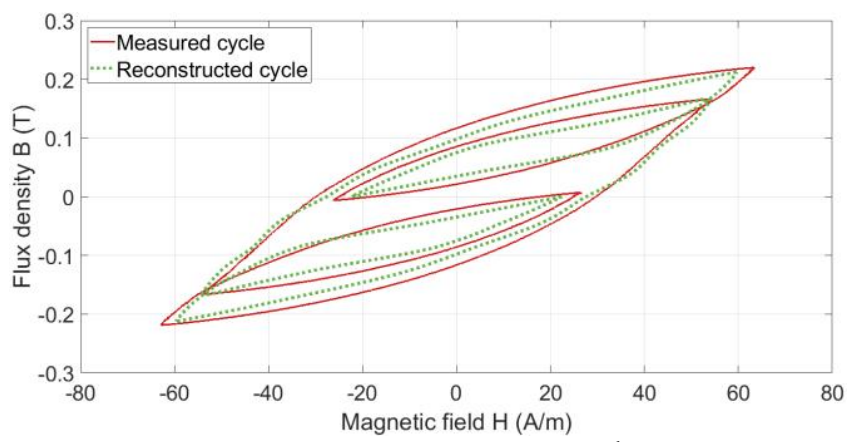

Fig. 8. Measured and reconstructed $0.22 \mathrm{~T}$ cycle with $3^{\text {rd }}$ harmonic at $100 \%$ $45^{\circ} / 2 \mathrm{~Hz}$

\section{B. Limits}

This model allows to obtain satisfactory results and low computation time. Yet, some limitations prevent it from additional significant improvements:
- The threshold value cannot be considerably reduced; this prevents the model to reconstruct low amplitude phenomena accurately.

- Reconstructed cycles can show local negative $\mathrm{dB} / \mathrm{dH}$; this behavior is inconsistent and prevents the implementation of the model in finite element solver for example.

\section{NEW “CONTINUOUS” PLAY MODEL}

\section{A. Linear identification process}

In the previous version, the identification allows to calculate the value of the shape function for different values of $\mathrm{p}_{\mathrm{i}}(\mathrm{B}(\mathrm{t}))$. However, it is complicated to constraint the shape function or the global reconstructed signal.

Different studies [10], [11] proposes shape functions as input-dependent or independent but always as a piecewise linear function. In this study, the proposed shape function is an odd polynomial (6), leading to the static magnetic hysteresis becoming a multi-variable system (7).

$$
\begin{gathered}
h_{i}(x)=\sum_{j=1}^{D_{i}} a_{i, j} \cdot x^{2 . j-1} \\
H(t)=\sum_{i=1}^{M} \sum_{j=1}^{D_{i}} a_{i, j} \cdot p_{i}(B(t))^{2 . j-1}
\end{gathered}
$$

Where $D_{i}$ is linked to the degree of the $i^{\text {th }}$ polynomial and $a_{i, j}$ is the coefficient of the $\mathrm{j}^{\text {th }}$ monomial of the $\mathrm{i}^{\text {th }}$ polynomial.

To solve, a linear least square resolution is used (8):

$$
\min _{A_{i, j}}\left\|W \cdot\left(P_{i}(B(t)) \cdot A_{i, j}-H_{\text {measured }}(t)\right)\right\|
$$

Where $\mathrm{Pi}(\mathrm{B}(\mathrm{t}))$ contains each $\mathrm{pi}(\mathrm{B}(\mathrm{t}))$ monomial without its coefficients for each time step and $\mathrm{Ai}, \mathrm{j}$ is the vector of polynomials coefficients. This process is still a fitting method of the measured and modeled fields.

The number of hysterons and the threshold value are not correlated anymore. It is then possible to:

- $\quad$ Reduce the threshold value to almost zero, allowing the reconstruction of infinitesimal variations.

- Decrease the number of hysterons, reducing the computation cost.

A compromise must be found as the maximal recordable amplitude is 2.M. $\varepsilon$ and low condition number of $\mathrm{P}_{\mathrm{i}}(\mathrm{B}(\mathrm{t}))$ can induce numerical errors.

An iterative (9) weighting process is set up with averaging to avoid discrepancy:

$$
W=\operatorname{diag}\left(\frac{P_{i}(B(t))-H_{\text {measured }}(t)}{H_{\text {measured }}(t)}\right)
$$

\section{B. Management of the derivative sign}

Thanks to the linear least square resolution, linear constraints can be easily imposed. Here, the derivative is forced to be higher than $80 \%$ of the one calculated from the data (10): 


$$
\frac{d P_{i}(B(t))}{d t} \geq \frac{d H_{\text {measured }}(t)}{d t} \times 0.8
$$

As a result, the computation time for the identification procedure increases, but no local negative $\mathrm{dB} / \mathrm{dH}$ appears in the reconstructed $\mathrm{BH}$ curves anymore.

\section{RESULTS OF THE CONTINUOUS MODEL}

An equivalent experimental comparison from the previous discrete Play model was conducted using the same initial data. Figures 9-12 show some measured and reconstructed cycles and Table 2. gives the errors on loss calculation.

TABLE 2. RELATIVE ERRORS ON LOSS CALCULATION

\begin{tabular}{|c|c|c|c|c|}
\hline & Fig. 9. & Fig. 10. & Fig. 11. & Fig. 12. \\
\hline$\Delta P \%$ & $-3.5 \%$ & $0.8 \%$ & $5.1 \%$ & $5.8 \%$ \\
\hline
\end{tabular}

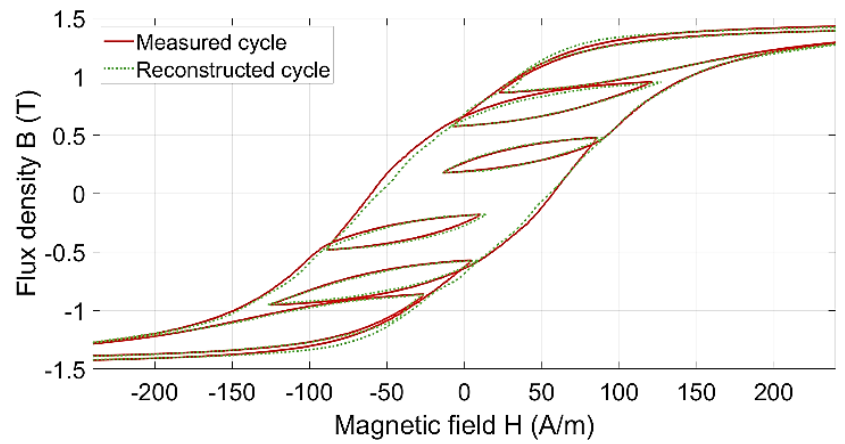

Fig. 9. Measured and reconstructed $1.7 \mathrm{~T}$ cycle with $9^{\text {th }}$ harmonic at $30 \%-90^{\circ}$

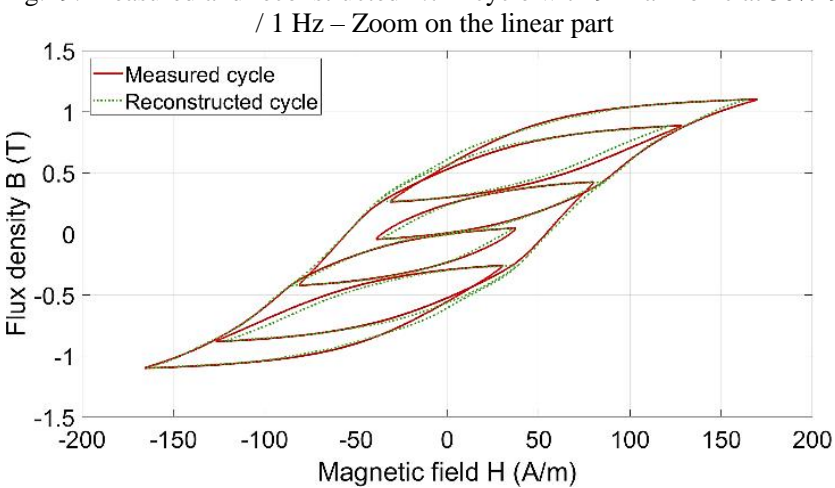

Fig. 10. Measured and reconstructed $1.1 \mathrm{~T}$ cycle with $5^{\text {th }}$ harmonic at $60 \%$ $100^{\circ} / 1 \mathrm{~Hz}$

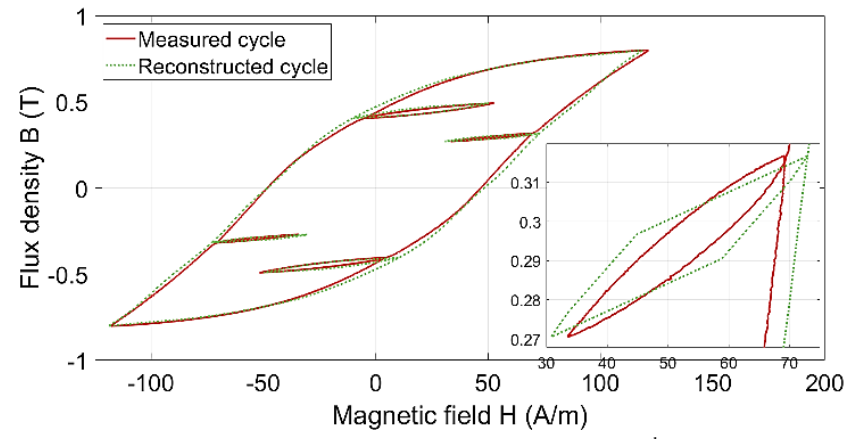

Fig. 11. Measured and reconstructed $0.8 \mathrm{~T}$ cycle with $5^{\text {th }}$ harmonic at $25 \%$ $45^{\circ} / 1 \mathrm{~Hz}$ - Inset: zoom on $0.05 \mathrm{~T}$ minor loop

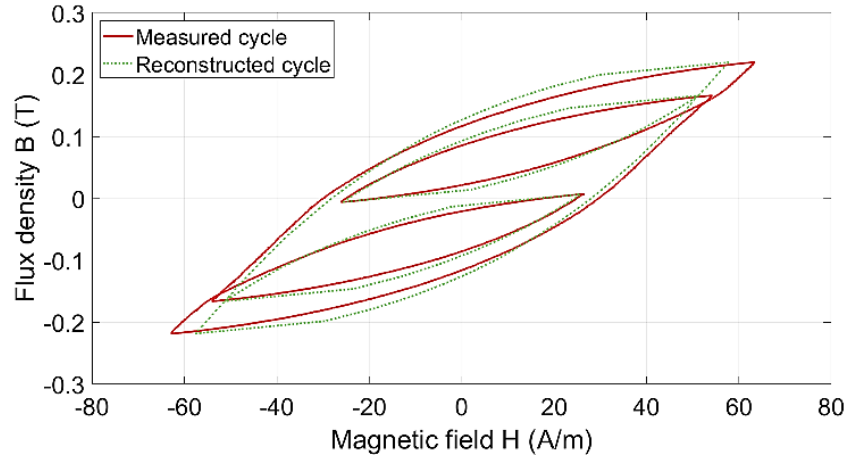

Fig. 12. Measured and reconstructed $0.22 \mathrm{~T}$ cycle with $3^{\text {rd }}$ harmonic at $100 \%$ $45^{\circ} / 2 \mathrm{~Hz}$

\section{CONCLUSION}

In this paper, we present many improvements of Play model. The characterization method is modified and the refinement process is introduced. It shows significant impact on the modeled hysteresis. The solving process is adjusted to minimize the MSE and to favor the linear part of the hysteresis. Those modifications lead to accurate loss estimation, largely validated by experimental comparison on various waveforms. The computation cost with an Intel i5-8265U @ $1.65 \mathrm{GHz}$ is $0.17 \mathrm{~s}$ for a 10000 points flux density signal and $0.074 \mathrm{~s}$ for 1000 points.

A new "continuous" model is also proposed. Despite a greater identification cost and thanks to the derivative sign management, the modeled magnetic field is more consistent. A very high resolution is achieved, allowing the modeling of tiny amplitude variations. The computation cost with the same configuration is $0.74 \mathrm{~s}$ for a 10000 points flux density signal and $0.13 \mathrm{~s}$ for 1000 points.

\section{REFERENCES}

[1] Simin Jiang, Lijuan Wang, Liqiang Wang, Peng Ye, and Zhaoli Hao, 'A new thermal protection approach for permanent magnet synchronous motor', in IECON 2013 - 39th Annual Conference of the IEEE Industrial Electronics Society, Vienna, Austria, Nov. 2013, pp. 2536-2540, doi: 10.1109/IECON.2013.6699530.

[2] G. Bertotti, 'General properties of power losses in soft ferromagnetic materials', IEEE Trans. Magn., vol. 24, no. 1, pp. 621-630, Jan. 1988, doi: $10.1109 / 20.43994$.

[3] P. Lee, K. Kuo, C. Wu, Z. Wong, and J. Yen, 'Prediction of iron losses using the modified Steinmetz equation under the sinusoidal waveform', in 2011 8th Asian Control Conference (ASCC), May 2011, pp. 579584.

[4] I. D. Mayergoyz and G. Friedman, 'Generalized Preisach model of hysteresis', IEEE Trans. Magn., vol. 24, no. 1, pp. 212-217, Jan. 1988, doi: $10.1109 / 20.43892$

[5] A. Benabou, S. Clénet, and F. Piriou, 'Comparison of Preisach and Jiles-Atherton models to take into account hysteresis phenomenon for finite element analysis', J. Magn. Magn. Mater., vol. 261, no. 1-2, pp. 139-160, Apr. 2003, doi: 10.1016/S0304-8853(02)01463-4.

[6] S. E. Zirka, Y. I. Moroz, P. Marketos, and A. J. Moses, 'CongruencyBased Hysteresis Models for Transient Simulation', IEEE Trans. Magn., vol. 40, no. 2, pp. 390-399, Mar. 2004, doi: 10.1109/TMAG.2004.824137.

[7] B. Daniels, T. Overboom, and E. Lomonova, 'Coupled statistical and dynamic loss prediction of high-permeability grain-oriented electrical steel', Eur. Phys. J. Appl. Phys., vol. 90, no. 1, p. 10901, Apr. 2020, doi: 10.1051/epjap/2020200018.

[8] S. Bobbio, G. Milano, C. Serpico, and C. Visone, 'Models of magnetic hysteresis based on play and stop hysterons', IEEE Trans. Magn., vol. 33, no. 6, pp. 4417-4426, 1997. 
[9] A. Giraud, A. Bernot, Y. Lefevre, and J. F. Llibre, 'Modeling quasistatic magnetic hysteresis: A new implementation of the play model based on experimental asymmetrical B(H) loops', in 2016 XXII International Conference on Electrical Machines (ICEM), Lausanne, Switzerland, Sep. 2016, pp. 1895-1901, doi: 10.1109/ICELMACH.2016.7732782.

[10] T. Matsuo, D. Shimode, Y. Terada, and M. Shimasaki, 'Application of stop and play models to the representation of magnetic characteristics of silicon steel sheet', IEEE Trans. Magn., vol. 39, no. 3, pp. 13611364, May 2003, doi: 10.1109/TMAG.2003.810171.

[11] T. Matsuo and M. Shimasaki, 'An identification method of play model with input-dependent shape function', IEEE Trans. Magn., vol. 41, no. 10, pp. 3112-3114, Oct. 2005, doi: 10.1109/TMAG.2005.854892. 